\title{
Evidence for an Association Between Tako-Tsubo Cardiomyopathy and Bronchial Asthma: Retrospective Analysis in a Primary Care Hospital
}

\author{
Leonardo Glutz von Blotzheim ${ }^{1,2, *}$, Stefan Christen ${ }^{1}$, Stephan Wieser ${ }^{3}$, Silvia Ulrich ${ }^{4}$ and \\ Lars C. Huber ${ }^{3,4}$ \\ ${ }^{I}$ Division of Cardiology, Waid City Hospital, Zurich, Switzerland \\ ${ }^{2}$ Department of Internal Medicine, Citizen's Hospital Solothurn, Switzerland \\ ${ }^{3}$ Division of Pulmonology, Waid City Hospital, Zurich, Switzerland \\ ${ }^{4}$ Division of Pulmonology, University Hospital of Zurich, Zurich, Switzerland
}

\begin{abstract}
Objective: We investigated the prevalence of bronchial asthma in patients with Tako-Tsubo Syndrome (TTS).
Design: This retrospective case-series study was conducted in a primary care hospital in Zurich, Switzerland. Data of all patients with newly diagnosed TTS $(2002$ - 2012) were assessed electronically by the use of ICD-10. Asthma prevalence was compared to published epidemiologic data.

Setting: Bronchial asthma is characterized by airway inflammation and, during attack, release of endogenous catecholamines. Sympathomimetic drugs are the mainstay of treatment for asthma patients. Likewise, catecholamine mediated diffuse microvascular myocardial dysfunction seems to be of critical importance for the development of TTS.

Results: 20 cases of TTS were identified. 90\% were female, showed a median age of $70 \pm 13 \mathrm{y}$ [25y - 90y], an apical and/or midventricular ballooning pattern with preserved basal function and a median initial LVEF of 34 $\pm 9 \%$ [25\% - 55\%]. 65\% of patients underwent coronary angiography to rule out significant coronary artery disease. Hypertension was present in $45 \%$ of patients, $35 \%$ were smokers, none was suffering from diabetes. Prevalence of asthma in patients with TTS was significantly higher compared to the normal population ( $25 \%$ vs. $7 \%, \mathrm{p}=0.012)$. In $30 \%$ of the TTS patients an iatrogenic cause for development of TTS was identified.

Conclusion: Prevalence of asthma was significantly higher in patients with TTS compared to epidemiologic data from an age-matched population. Phenotypes of patients developing obstructive ventilatory disease and TTS might share common pathogenic mechanisms beyond the use of bronchodilatators. In addition, we identified other iatrogenic etiologies in patients with TTS.
\end{abstract}

Keywords: Bronchial asthma, sympathomimetic drugs, Tako-Tsubo-Syndrome.

\section{INTRODUCTION}

Tako-Tsubo-Syndrome (TTS) was reported 1991 by Dote et al. [1] and describes the resemblance of the left ventricle during systole to Japanese octopus fishing pots. Patients with TTS present with chest pain or sudden dyspnoea, electrocardiographic changes and elevated cardiac enzymes mimicking myocardial infarction in absence of significant coronary stenosis. Transthoracic echocardiogram shows transient akinesis in the apical and/or middle ventricular segments (apical ballooning) and hyperkinesis in the basal segments of the left ventricle impairing ventricular ejection fraction [2] These wall-motion abnormalities usually completely resolve within days or weeks [3]. Incidence of

*Address correspondence to this author at the Niklaus-Konrad-Strasse 11, CH-4500 Solothurn, Switzerland; Tel: +41 (0)79 67744 37;

Fax: +41 (0)32 62742 07; E-Mail: Leonardo.glutz@gmx.ch
TTS in patients presenting with acute coronary syndromes is estimated to be around $2 \%[4,5]$ The onset of TTS is often preceded by emotional or physical stress and the condition is, as such, also known as "broken heart syndrome" or stressinduced cardiomyopathy. However, in $30 \%$ of cases the trigger factor remains unclear [3]. Of interest, in patients with TTS, plasma catecholamine levels have found to be several times higher as compared to patients with myocardial infarction and remained markedly elevated over a period of a week [6]. The elevated levels of catecholamines have been associated with diffuse microvascular myocardial dysfunction and subsequent ischemia as a possible mechanism, whereas the increased adrenergic receptor density in cardiac apical segments might explain the unequal affection of the myocardium and, thus, the typical shape of affected hearts in transthoracic echocardiogram or ventriculography [7]. 
Another disease in which sympathomimetic reactions might play an important role both in pathogenesis and treatment is bronchial asthma. Bronchial asthma is a common disease with an increasing prevalence affecting about $7 \%$ of the Swiss adult population [8]. The airway inflammation observed in bronchial asthma is, at least in part, triggered by cytokines such as IL-4, -5, and -13 [9], driving the eosinophilic response. The inflammatory IL-6 that appears to correlate with levels of IL-13 has been reported to be another trigger factor $[10,11]$. Moreover, during an acute asthma attack, endogenous catecholamines are released [12].

These mediators might also be of critical importance for the development of TTS and, due to the major role of sympathomimetic drugs in the treatment of bronchial asthma as well as the release of endogenous catecholamines in exacerbations and acute asthma attacks, we assumed a higher prevalence of bronchial asthma in patients with TTS.

\section{METHODS}

To address this hypothesis, a retrospective case-series study was conducted in a primary care hospital in Zurich, Switzerland. Data of all patients with newly diagnosed TTS were assessed from the hospital electronic patients database by use of the ICD-10 code. Data for several codes (e.g. I51.8, I42.8) were investigated. Upon identifying the cases of TTS, analysis for trigger factors, cardiovascular risk factors, left ventricular ejection fraction (LVEF) at time of initial diagnosis and at follow-up, results of coronary angiography and comorbidities was conducted. Patients from a period of 10 years $(2002-2012)$ were included. Asthma prevalence in patients with TTS was compared to epidemiologic data for asthma in Switzerland. Statistical analysis was performed with GraphPad using non-parametric tests.

\section{RESULTS}

Over a period of 10 years, 20 cases of TTS were identified (details provided in Table 1). Of these cases, 90\% were female, showed a median age of $70 \pm 13 y$ [25y $-90 y$, an apical and/or midventricular ballooning pattern with preserved basal function and a median initial left ventricular ejection fraction of $34 \pm 9 \%$ [25\% - 55\%]. $65 \%$ of patients underwent coronary angiography to rule out significant atherothrombotic coronary artery disease. Hypertension was present in $45 \%$ of patients, $35 \%$ were smokers, none was suffering from diabetes. 5 of the TTS patients had been diagnosed with bronchial asthma. 3 of these had been treated with bronchodilatators only, two of which with short acting relievers. 2 patients additionally used inhaled corticosteroids. At time of hospitalization, none of the patients was under systemic corticosteroid therapy. In 2 patients, both without inhaled corticosteroids, the asthma was uncontrolled and symptomatic asthma was the reason for hospitalization. According to the patient files, the asthma was controlled in the 3 other patients. When assessed with Fisher's exact test, the prevalence of asthma in patients with TTS was significantly higher compared to the normal population $(25 \%$ vs. $7 \%, \mathrm{p}=0.012$ ). The number detected in our small inpatient cohort might even be underestimated since one patient was hospitalized with acute exacerbated chronic obstructive pulmonary disease. However, this patient was a lifelong nonsmoker and it is probable that the irreversible obstruction was due to airway remodeling from chronic asthma. Because no formal diagnosis of asthma has been

Table 1. Clinical characteristics of 20 inpatients with newly diagnosed stress induced cardiomyopathy (TTS).

\begin{tabular}{|c|c|c|c|c|c|c|c|c|c|c|c|}
\hline $\begin{array}{l}\text { Patient } \\
\text { No. }\end{array}$ & $\begin{array}{l}\text { Age } \\
\text { [yr] }\end{array}$ & Sex & Reason for Hospitalisation & Coronary Risk Factors & $\begin{array}{l}\text { Bronchial } \\
\text { Asthma }\end{array}$ & Asthma Therapy & Trigger Factor for TTS & $\begin{array}{l}\text { Initial } \\
\text { LVEF [\%] }\end{array}$ & $\begin{array}{l}\text { Follow-Up } \\
\text { LVEF [\%] }\end{array}$ & $\begin{array}{l}\text { Coronary } \\
\text { Angiography }\end{array}$ & $\begin{array}{l}\text { Year of Diagnosis } \\
\text { (TTS) }\end{array}$ \\
\hline 1 & 75 & $f$ & Poorly controlled asthma & Hypertension & yes & LABA & $n / a$ & 15 & 60 & normal & 2007 \\
\hline 2 & 70 & $f$ & Abdominal infection & - & - & & Catecholamines & 45 & 60 & normal & 2008 \\
\hline 3 & 74 & $f$ & Hypertensive emergency & Hypertension & - & & Epistaxis & 27 & 58 & normal & 2008 \\
\hline 4 & 72 & $f$ & Hemicolectomy & Dyslipidemia & yes & SABA, LABA, ICS & Catecholamines & 37 & 62 & normal & 2008 \\
\hline 5 & 63 & $f$ & Seizure & Smoking & - & & Epilepsy & 30 & 64 & n/a & 2008 \\
\hline 6 & 70 & $f$ & Anxiety disorder & - & - & & Anxiety & 55 & 65 & normal & 2009 \\
\hline 7 & 74 & $f$ & Thoracic Pain & Smoking & yes & LABA, ICS & n/a & 40 & 65 & normal & 2009 \\
\hline 8 & 71 & $\mathrm{~m}$ & Exacerbation of COPD & - & - & & Upper airway infection & 25 & 65 & normal & 2009 \\
\hline 9 & 86 & $f$ & Gastroenteritis & Hypertension & & & Gastroenteritis & 35 & 65 & $n / a$ & 2010 \\
\hline 10 & 60 & $f$ & Bleeding finger cut & Smoking & - & & Paralysis & 45 & 67 & normal & 2010 \\
\hline 11 & 75 & $f$ & Hyperthyroidism & Hypertension, smoking & - & & Vomiting & 40 & 70 & n/a & 2010 \\
\hline 12 & 84 & $f$ & Leg ulcers & Hypertension & - & & n/a & 30 & 55 & $\mathrm{n} / \mathrm{a}$ & 2010 \\
\hline 13 & 73 & $\mathrm{f}$ & Thoracic pain & - & - & & Nightmare & 31 & 51 & normal & 2010 \\
\hline 14 & 89 & f & Epidural hematoma & Hypertension & yes & SABA & Surgical intervention & 40 & 50 & n/a & 2011 \\
\hline 15 & 25 & $\mathrm{~m}$ & Achilles tendon rupture & & & & Catecholamines & 25 & 65 & normal & 2011 \\
\hline 16 & 66 & $\mathrm{f}$ & Thoracic pain & Hypertension, smoking & - & & Panic & 35 & 65 & normal & 2011 \\
\hline 17 & 60 & $f$ & Dislocated fracture & Hypertension, smoking & - & & Surgical intervention & 40 & 65 & n/a & 2012 \\
\hline 18 & 64 & $f$ & Asthma attack & Smoking & yes & SABA & Catecholamines & 45 & 56 & normal & 2012 \\
\hline 19 & 62 & $f$ & Abdominal infection & $\cdot$ & - & & Vomiting & 30 & 60 & normal & 2012 \\
\hline 20 & 90 & $f$ & Cranial trauma & Hypertension, smoking & - & & Cranial trauma & 25 & 50 & n/a & 2012 \\
\hline
\end{tabular}

$\mathrm{LVEF}=$ left ventricular ejection fraction; TTS=Tako-Tsubo-Syndrome; COPD=chronic obstructive pulmonary disease; $S A B A=$ short acting beta agonist; LABA=long acting beta agonist; ICS=inhaled corticosteroids 
mentioned in the electronic data file, this patient was not counted as having asthma.

As an additional finding independent of the diagnosis of asthma, in $30 \%$ of the TTS patients an iatrogenic cause for development of TTS was identified (treatment with sympathomimetic drugs in $20 \%$; surgical procedures in $10 \%)$.

\section{DISCUSSION}

We describe here a significantly higher prevalence of asthma in patients with TTS compared to the normal population in Switzerland. These retrospectively collected, descriptive data are limited by the lack of formal controls and the low number of cases identified, the latter of which is mainly due to an allocation bias since patients presenting with acute chest pain and electrocardiographic changes compatible with ST-elevation myocardial infarction are not admitted to our clinic. Furthermore, only two thirds of patients underwent coronary angiography to rule out significant atherosclerosis which is warranted for the diagnosis of TTS according to the Mayo Clinic criteria for apical ballooning syndromem [2]. However, since all patients without invasive diagnostic assessment showed typical echocardiographic features of TTS (i.e. transient hypokinesis, akinesis or dyskinesis of the left ventricular mid segments) and complete normalization of LVEF within the follow-up, ischemic heart disease is an unlikely cause of the observed features in this cohort of patients. Hence our results might be representative for other primary care hospitals that are lacking coronary catheterization facilities. Our data suggest that comorbidities (i.e. bronchial asthma) and iatrogenic causes (i.e. medication) might be underestimated in the inpatient setting. While complete understanding of pathogenesis of TTS is still lacking, recent data suggest catecholamine mediated diffuse microvascular myocardial dysfunction as a possible mechanism. Of interest, in patients with TTS, plasma levels of catecholamines were found to be significantly increased compared to patients with myocardial infarction and these levels remained markedly elevated over several days [6]. In this retrospective study we have not analyzed levels of catecholamines or inflammatory cytokines. But our data suggest a potential interplay of asthma and TTS probably triggered by the use of sympathomimetic drugs and elevated levels of endogenous catecholamines. In addition, experimental data make it very likely that, next to catecholamines and betamimetic drugs, other factors could promote a final common pathway in both entities (summarized in Fig. 1). For example, in climacteric women suffering from psychological stress, the serum levels of several cytokines have been found elevated, in particular IL-6 [13]. While postmenopausal women are prone to develop TTS, elevated levels of IL-6 interestingly were found to be increased predominantly in female asthmatic patients [11]. IL-6 is one of the most important triggers of the acute phase response and was shown to result in aberrant expression of microRNAs [14, 15], which might also be involved in the pathogenesis of cardiomyopathies. Finally, a sustained hypereosinophilic response might be the result of

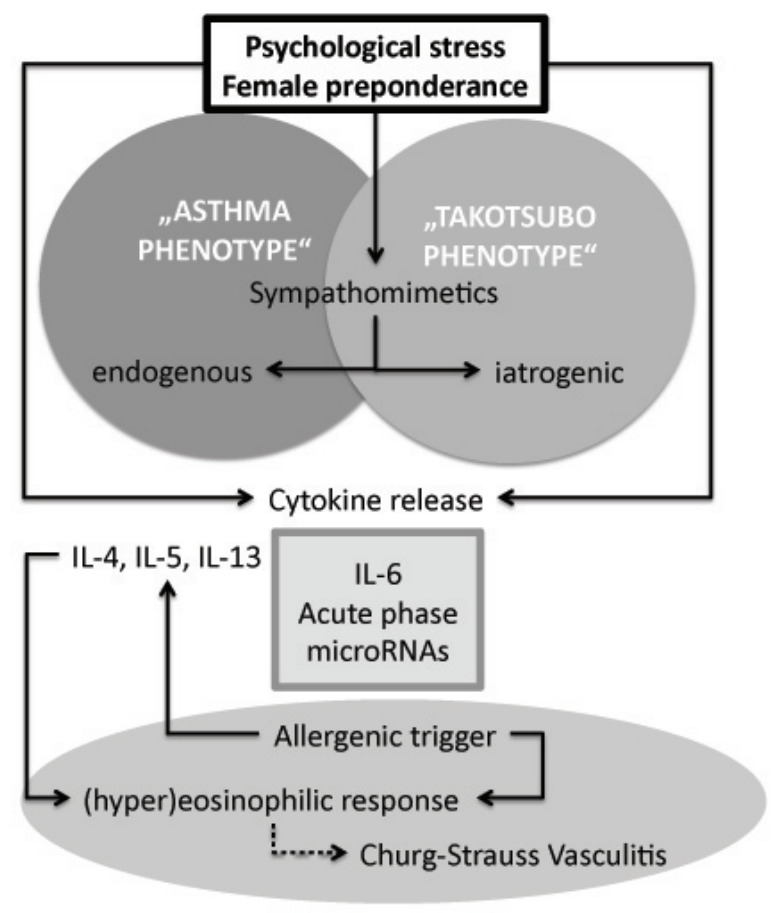

Fig. (1). Proposed models of the interplay in the pathogenesis of bronchial asthma and Takotsubo syndrome. Psychological stress, which might also aggravate bronchial asthma [17], is the main known trigger factor for the development of TTS. The most important downstream mediators of psychological stress are sympathomimetics (i.e. endogenous or iatrogenic catecholamines) that act through betaadrenergic receptors. Psychological stress also increases the level of serum cytokines, in particular of IL-6, which is found elevated in female asthmatic patients and triggers the acute phase response. The involvement of microRNAs is hypothetical. The hypereosinophilic response in Churg-Strauss vasculitis might offer a differential diagnosis when bronchial asthma and heart failure present concomitantly.

eosinophilic granulomatosis with polyangiitis, which commonly presents with uncontrolled bronchial asthma. Churg Strauss vasculitis could mimic TTS, in particular with myocardial involvement. In our patients, however, we had no evidence for an "asthma-plus" syndrome such as Churg strauss vasculitis.

\section{CONCLUSION}

In conclusion, since we are not aware of any studies addressing the prevalence of bronchial asthma in inpatients with TTS, we show here first evidence of an association between these two entities. Phenotypes of patients developing obstructive ventilatory disease (in particular bronchial asthma) and TTS might share common pathogenic mechanisms beyond the use of bronchodilatators. In addition, we identified other iatrogenic - and thus preventable - etiologies in one-third of patients with TTS. The use of synthetic catecholamines, which, of note, is of controversial benefit in acute asthma [16], thus should be 
handled with caution, in particular in postmenopausal female patients that are at high risk to develop TTS.

\section{ABBREVIATION}

$\begin{array}{lll}\text { COPD } & = & \text { Chronic obstructive pulmonary disease } \\ \text { ICD-10 } & = & \text { International Classification of Diseases } \\ \text { ICS } & = & \text { Inhaled Corticosteroids } \\ \text { IL-6 } & = & \text { Interleukine-6 } \\ \text { LABA } & = & \text { Long Acting Beta Agonist } \\ \text { LVEF } & = & \text { Left Ventricular Ejection Fraction } \\ \text { SABA } & = & \text { Short Acting Beta Agonist } \\ \text { TTS } & = & \text { Tako-Tsubo-Syndrome }\end{array}$

\section{AUTHOR CONTRIBUTION}

LGVB and LCH were involved in conception, design and interpretation of data. SC, SW and SU have reviewed drafts of the article and gave final approval of the version to be published

\section{CONFLICT OF INTEREST}

The authors certify that there is no possible or actual conflict of interest regarding the material discussed in the manuscript.

\section{ACKNOWLEDGEMENTS}

This research received no grant from any funding agency in the public, commercial or not-for-profit sectors.

\section{REFERENCES}

[1] Dote K, Sato H, Tateishi H, Uchida T, Ishihara M. Myocardial stunning due to multivessel coronary spasms: a review of 5 cases. J Cardiol 1991; 21(2): 203-14

[2] Bybee KA, Kara T, Prasad A, et al. Systematic review: transient left ventricle apical ballooning: a syndrome that mimics STsegment elevation myocardial infarction. Ann Intern Med 2004; 141(11): 858-65
[3] Vizzardi E, D'Aloia A, Zanini G, et al. Tako-tsubo-like left ventricular dysfunction: transient left ventricular apical ballooning syndrome. Int J Clin Pract 2010; 64(1): 67-74

[4] Ito K, Sugihara H, Katoh S, Azuma A, Nakagawa M. Assessement of Takotsubo (ampulla) cardiomyopathy using 99mTc-tetrofosmin myocardial SPECT - comparison with acute coronary syndrome. Ann Nucl Med 2003; 17(2): 115-22

[5] Matsuoka K, Okubo S, Fujii E, et al. Evaluation of the arrhythmogenecity of stress-induced "Takotsubo cardiomyopathy" from the time course of the 12-lead surface electrocardiogram. Am J Cardiol 2003; 92(2): 230-3

[6] Wittstein IS, Thiemann DR, Lima JA, et al. Neurohumoral features of myocardial stunning due to sudden emotional stress. N Engl J Med 2005; 352(6): 539-48

[7] Mori H, Ishikawa S, Kojima S, et al. Increased responsiveness of left ventricular apical myocardium to adrenergic stimuli. Cardiovasc Res 1993; 27(2): 192-8

[8] Masoli M, Fabian D, Holt S, Beasley R. Global initiative for asthma (GINA) program. The global burden of asthma: executive summary of the GINA Dissemination Committee report. Allergy 2004; 59(5): 469-78

[9] Kips JC. Cytokines in asthma. Eur Respir J. 2001; 18 (Suppl 34): 24-33

[10] Neveu WA, Allard JL, Raymond DM, et al. Elevation of IL-6 in the allergic asthmatic airway is independent of inflammation but associates with loss of central airway function. Respir Res 2010; 8: 11: 28

[11] Scott HA, Gibson PG, Garg ML, Wood LG. Airwaiy inflammation is augmented by obesity and fatty acids in asthma. Eur Respir J 2011; 38(3); 594-602

[12] Larsson K, Carlens P, Bevegård S, Hiemdahl P. Sympathoadrenal responses to bronchoconstriction in asthma: an invasive and kinetic study of plasma catecholamines. Clin Sci 1995; 88(4): 439-46.

[13] Yasui T, Maegawa M, Tomita J, et al. Association of cytokine concentrations with psychological symptoms in midlife women. J Reprod Immunol 2007; 75(1): 56-62

[14] Danielson LS, Park DS, Rotllan N, et al. Cardiovascular dysregulation of miR-17-92 causes a lethal hypertrophic cardiomyopathy and arrhythmogenesis. FASEB J 2012 (Epub ahead of print).

[15] Brock M, Trenkmann M, Gay RE, Gay S, Speich R, Huber LC. MicroRNA-18a enhances the interleukin-6-mediated production of the acute-phase proteins fibrinogen and haptoglobin in human hepatocytes. J Biol Chem 2011; 286(46): 40142-50.

[16] Lazarus SC. Clincal practice. Emergency treatment of asthma. N Engl J Med 2010; 363(8): 755-64.

[17] Rosenkranz MA, Busse WW, Sheridan JF, Crisafi GM, Davidson RJ. Are there neurophenotypes for asthma? Functional brain imaging of the interaction between emotion and inflammation in asthma. PLoS One 2012; 7(8): e40921.

(C) Blotzheim et al.; Licensee Bentham Open.

This is an open access article licensed under the terms of the Creative Commons Attribution Non-Commercial License (http://creativecommons.org/licenses/by-nc/3.0/) which permits unrestricted, non-commercial use, distribution and reproduction in any medium, provided the work is properly cited. 